also of their families and carers. By undertaking this survey, and disseminating its findings widely, the BCAG hopes that consumers' views will inform service development and quality improvement strategies in breast cancer services across NSW.

\section{CONCLUSION}

This survey also demonstrates that consumer-initiated and designed research can make a contribution to the treatment experiences of people living with cancer. It also provides consumer groups, such as the BCAG, with an evidencebased platform for their advocacy and lobbying activities.

\section{REFERENCES}

1. Cancer Strategies Group. Priorities for Action in Cancer Control 2001-2003. Canberra: Commonwealth Department of Health and Ageing, 2001.

2. NHMRC National Breast Cancer Centre. Psychosocial clinical practice guidelines: Information, support and counselling for women with breast cancer. Canberra: National Health and Medical Research Council, 2000.

3. Breast Care Implementation Advisory Committee. Breast Disease Service Redevelopment Strategy 1999-2003. Melbourne: Victorian Government Publishing Service, 1999.

4. Expert Advisory Group on Cancer. Improving the Quality of Cancer Services-A Report by the Expert Advisory Group on Cancer to the Chief Medical Officers of England and Wales (The Calman-Hine Report). London: Department of Health, 1995. W

\title{
RELEASE OF THE 2002 AREA HEALTH SERVICE REPORTS
}

\section{Margo Eyeson-Annan and Lara Harvey \\ Centre for Epidemiology and Research \\ NSW Department of Health}

The 2002 Area Health Service Reports (AHSRs) are the first of a series of annual reports produced to assist the area health services monitor the health status of their population, and to support policy development and service planning at the area level.

The AHSRs present data from the 1997, 1998, and 2002 NSW Health Surveys that is specific to each of the 17 area health services. These surveys were conducted by the Centre for Epidemiology and Research through the NSW Department of Health's Computer Assisted Telephone Interviewing (CATI) Facility. The 2002 NSW Health Survey reports on data collected from approximately 15,000 randomly-selected adults.

The NSW Department of Health, in consultation with the 17 area health services, has identified 15 indicators that will be reported on annually. These are:

\section{Health Behaviours}

- alcohol risk drinking behaviour

- fruit intake

- vegetable intake

- physical activity

- smoking status

- smoke-free households

\section{Health Status}

- self-rated health status

- asthma

- diabetes or high blood sugar

- oral health-no natural teeth missing

- overweight and obesity

- psychological distress

\section{Health Services}

- difficulties getting health care when needing it

- emergency department care rating

- hospital care rating.

These indicators are presented in graphical and tabular form. For each indicator, the AHSRs include line charts of trend by sex (1997, 1998, 2002 data) comparing the area health service with the whole of NSW, and a bar chart of the indicator by age group (2002 Area Health Service data).

Examples of the trend graph for one of the indicators used in the Health Survey Program Area Reports-Smoke-free households by sex for people aged 16 years and overare shown for an urban area (Central Sydney Area Health Service, Figure 1) and a rural area (New England Area Health Service, Figure 2).

The AHSRs were released during May 2003 and are available via the NSW Department of Health intranet as both PDF and HTML files. 


\section{FIGURE 1}

SMOKE-FREE HOUSEHOLDS BY SEX, PEOPLE AGED 16 YEARS AND OVER, CENTRAL SYDNEY AREA HEALTH SERVICE, NSW, 1997-2002

\section{Males}

Per cent

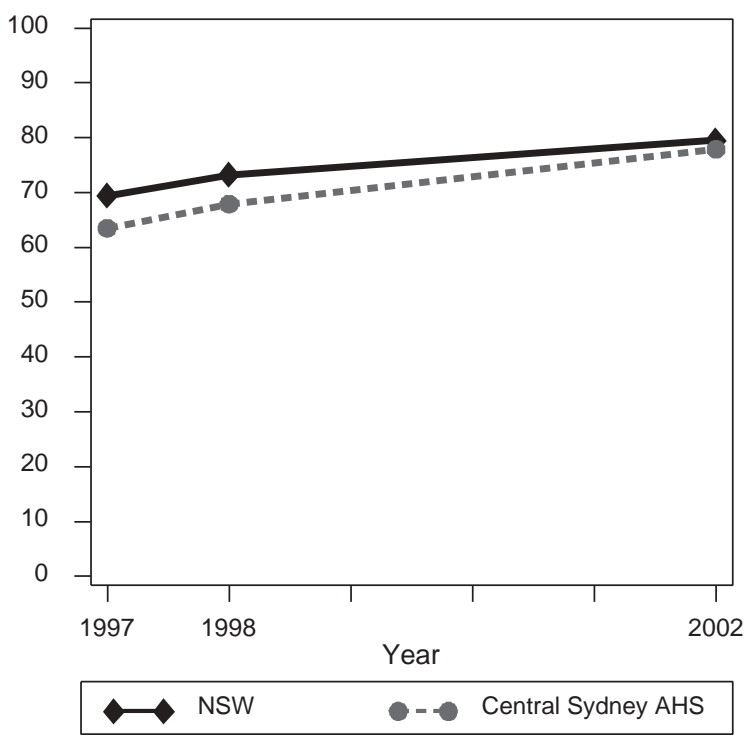

Females

Per cent

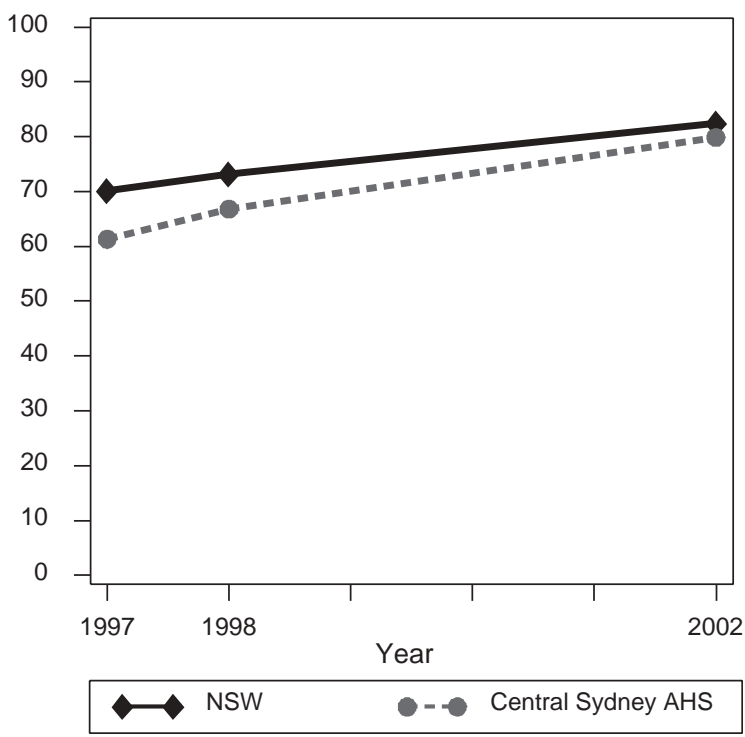

\begin{tabular}{|c|c|c|c|c|c|c|c|c|c|}
\hline Area & Year & Males & $(95 \% \mathrm{Cl})$ & $\begin{array}{r}\text { Males } \\
\text { (est. no.) }\end{array}$ & Females & $(95 \% \mathrm{Cl})$ & $\begin{array}{l}\text { Females } \\
\text { (est. no.) }\end{array}$ & Persons & $\begin{array}{l}\text { Persons } \\
\text { (est. no.) }\end{array}$ \\
\hline Central & 1997 & 63.5( & $59.2-67.9)$ & 122000 & 61.3 & (57.3-65.3) & 119000 & $62.4(59.4-65.4)$ & 241000 \\
\hline \multirow[t]{2}{*}{ Sydney AHS } & 1998 & 67.9 ( & 62.6-73.2) & 132000 & 66.8 & $(62.6-71.0)$ & 132000 & $67.4(64.0-70.7)$ & 264000 \\
\hline & 2002 & 77.9 ( & 72.6-83.2) & 156000 & 79.9 & $(75.7-84.1)$ & 164000 & $78.9(75.5-82.3)$ & 320000 \\
\hline \multirow[t]{3}{*}{ NSW } & 1997 & 69.4( & 68.1-70.7) & 1644000 & 70.1 & (68.9-71.3) & 1704000 & $69.8(68.9-70.6)$ & 3348000 \\
\hline & 1998 & 73.2( & 71.9-74.6) & 1755000 & 73.2 & (72.0-74.3) & 1798000 & $73.2(72.3-74.1)$ & 3553000 \\
\hline & 2002 & 79.6( & $78.0-81.1)$ & 1966000 & 82.4 & (81.2-83.7) & 2106000 & $81.0(80.0-82.0)$ & 4072000 \\
\hline
\end{tabular}

Source: NSW Health Survey 1997, 1998, and 2002 (HOIST), Centre for Epidemiology and Research, NSW Department of Health.

Notes: Estimates are based on the following numbers of respondents:

1997-1225 (Central Sydney AHS) and 17495 (NSW).

1998-1037 (Central Sydney AHS) and 17451 (NSW).

2002-810 (Central Sydney AHS) and 12610 (NSW).

The indicator includes those households with respondents indicating that their home was smoke free. The question used to define the indicator was: "Which of the following best describes your home situation? My home is smoke free (includes smoking is allowed outside only), people occasionally smoke in the house, and people frequently smoke in the house". 
FIGURE 2

SMOKE-FREE HOUSEHOLDS BY SEX, PEOPLE AGED 16 YEARS AND OVER, NEW ENGLAND AREA HEALTH SERVICE, NSW, 1997-2002

Males

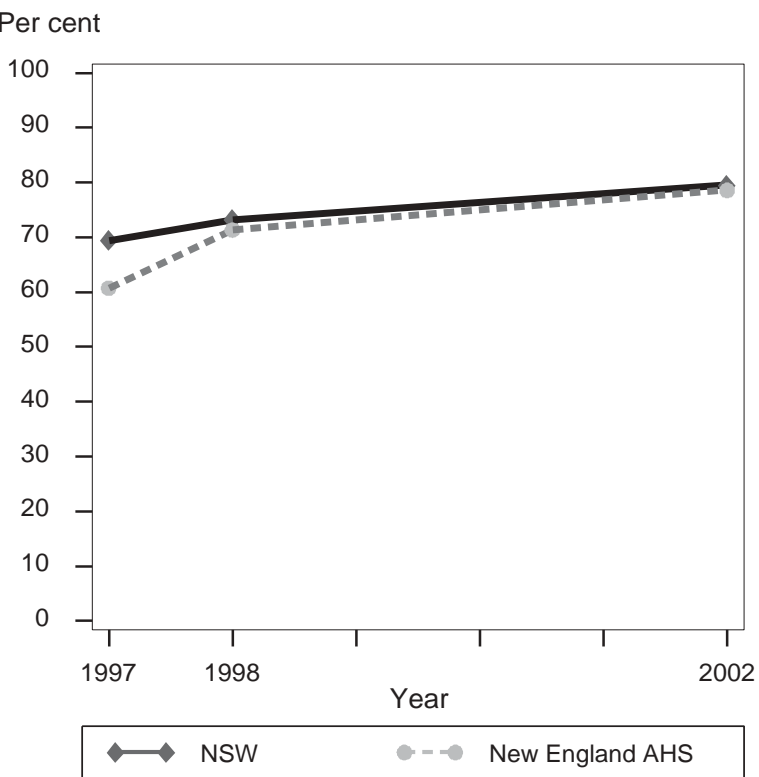

Females

Per cent

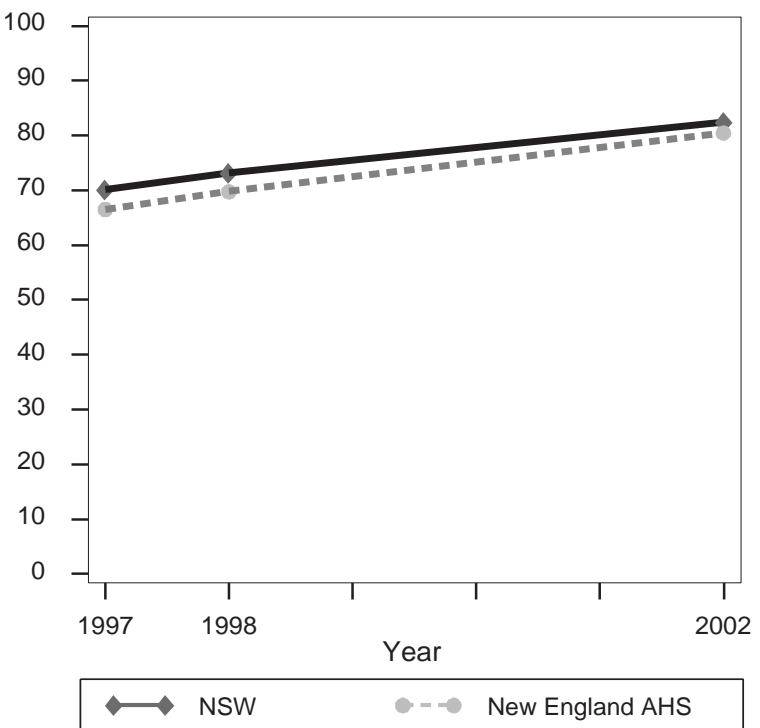

\begin{tabular}{|lcrrrrrrrrr|}
\hline Area & Year & Males & $\mathbf{( 9 5 \% ~ C l )}$ & $\begin{array}{r}\text { Males } \\
\text { (est. no.) }\end{array}$ & Females & $\mathbf{( 9 5 \% ~ C l )}$ & $\begin{array}{r}\text { Females } \\
\text { (est. no.) }\end{array}$ & Persons & $\begin{array}{r}(95 \% \text { Cl) } \\
\text { Persons } \\
\text { (est. no.) }\end{array}$ \\
\hline New England & 1997 & 60.7 & $(55.7-65.7)$ & 39000 & 66.5 & $(62.5-70.6)$ & 44000 & 63.7 & $(60.5-66.9)$ & 84000 \\
AHS & 1998 & 71.3 & $(66.5-76.2)$ & 46000 & 69.8 & $(65.8-73.8)$ & 46000 & 70.5 & $(67.4-73.7)$ & 92000 \\
& 2002 & 78.6 & $(72.7-84.5)$ & 50000 & 80.5 & $(76.0-84.9)$ & 53000 & 79.6 & $(75.9-83.2)$ & 103000 \\
NSW & 1997 & 69.4 & $(68.1-70.7)$ & 1644000 & 70.1 & $(68.9-71.3)$ & 1704000 & 69.8 & $(68.9-70.6)$ & 3348000 \\
& 1998 & 73.2 & $(71.9-74.6)$ & 1755000 & 73.2 & $(72.0-74.3)$ & 1798000 & 73.2 & $(72.3-74.1)$ & 3553000 \\
& 2002 & 79.6 & $(78.0-81.1)$ & 1966000 & 82.4 & $(81.2-83.7)$ & 2106000 & 81.0 & $(80.0-82.0)$ & 4072000 \\
\hline
\end{tabular}

Source: NSW Health Survey 1997, 1998, and 2002 (HOIST), Centre for Epidemiology and Research, NSW Department of Health.

Notes: Estimates are based on the following numbers of respondents:

1997-1030 (New England AHS) and 17495 (NSW).

1998-1017 (New England AHS) and 17451 (NSW).

2002-745 (New England AHS) and 12610 (NSW).

The indicator includes those households with respondents indicating that their home was smoke free. The question used to define the indicator was: "Which of the following best describes your home situation? My home is smoke free (includes smoking is allowed outside only), people occasionally smoke in the house, and people frequently smoke in the house". 